\title{
How should we monitor patients with acute respiratory failure treated with noninvasive ventilation?
}

\author{
Begum Ergan (101,4, Jacek Nasitowski ${ }^{2,4}$ and João Carlos Winck ${ }^{3}$ \\ Number 2 in the Series "Highlights in acute respiratory failure" \\ Edited by Leo Heunks and Raffaele Scala
}

\begin{abstract}
Affiliations: 'Division of Intensive Care, Dept of Pulmonary and Critical Care, Faculty of Medicine, Dokuz Eylul University, Izmir, Turkey. ${ }^{2}$ Department of Internal Medicine, Pulmonary Diseases and Allergy, Medical University of Warsaw, Warsaw, Poland. ${ }^{3}$ Northern Rehabilitation Centre Cardio-Pulmonary Group, Vila Nova de Gaia, Respiratory Medicine Units of Trofa-Saúde Alfena Hospital and Braga-Centro Hospital and Faculty of Medicine University of Porto, Porto, Portugal. ${ }^{4}$ Both authors contributed equally.
\end{abstract}

Correspondence: Begum Ergan, Division of Intensive Care, Dept of Pulmonary and Critical Care, Faculty of Medicine, Dokuz Eylul University, Izmir, Turkey. E-mail: begumerganahotmail.com

@ERSpublications

Adequate monitoring during NIV is one of the key elements for NIV success http://ow.ly/bNID30hBmDk

Cite this article as: Ergan B, Nasiłowski J, Winck JC. How should we monitor patients with acute respiratory failure treated with noninvasive ventilation? Eur Respir Rev 2018; 27: 170101 [https://doi.org/ 10.1183/16000617.0101-2017].

ABSTRACT Noninvasive ventilation (NIV) is currently one of the most commonly used support methods in hypoxaemic and hypercapnic acute respiratory failure (ARF). With advancing technology and increasing experience, not only are indications for NIV getting broader, but more severe patients are treated with NIV. Depending on disease type and clinical status, NIV can be applied both in the general ward and in high-dependency/intensive care unit settings with different environmental opportunities. However, it is important to remember that patients with ARF are always very fragile with possible high mortality risk. The delay in recognition of unresponsiveness to NIV, progression of respiratory failure or new-onset complications may result in devastating and fatal outcomes. Therefore, it is crucial to understand that timely action taken according to monitoring variables is one of the key elements for NIV success. The purpose of this review is to outline basic and advanced monitoring techniques for NIV during an ARF episode.

\section{Introduction}

Noninvasive ventilation (NIV) is a method of treatment that can be applied in a broad spectrum of indications [1]. NIV for acute respiratory failure (ARF) should be performed in a clinical environment with adequate nurse-to-patient ratios and monitoring. The choice of facility level should be selected according to disease severity and the co-existence of other organ failure. Irrespective of the clinical context,

Received: Sept 012017 | Accepted after revision: Dec 212017

Previous articles in this series: No. 1: Bos LD, Martin-Loeches I, Schultz MJ. ARDS: challenges in patient care and frontiers in research. Eur Respir Rev 2018; 27: 170107.

Conflict of interest: None declared.

Provenance: Submitted article, peer reviewed.

Copyright CERS 2018. ERR articles are open access and distributed under the terms of the Creative Commons Attribution Non-Commercial Licence 4.0. 
monitoring of patients treated with NIV should be adjusted to the patient's general status and the severity of respiratory insufficiency. These two factors should determine the location of the performance of NIV, since only the proper setting can provide suitable features for adequate monitoring. Monitoring of NIV during ARF is of the utmost importance and can be defined as the real-time evaluation of physiological functions to guide treatment strategies (table 1). Lives are not saved by monitoring itself; it is the actions taken based upon the monitoring data.

An inadequate level of care will have consequences in the likelihood of NIV failure. In fact, close monitoring to detect a favourable response or signs of deterioration is essential in ascertaining NIV success or preventing unnecessary delays in intubation [2].

To better understand the goals of care, a Society of Critical Care Medicine task force developed a categorical approach for NIV support in critical and palliative care [3]. The use of NIV for patients with acute respiratory failure was classified into three groups, as follows. 1) NIV as life support with no preset limitations on life-sustaining treatments; 2) NIV as life support in patients who have chosen to forego endotracheal intubation; and 3) NIV as a palliative measure in patients who have chosen to forego all life support. Attentive monitoring of NIV should be performed to provide optimal quality of NIV and other therapeutic procedures in a patient with no preset limitations. In contrast, it should be kept in mind that excessive implementation of monitoring tools may worsen the effect of NIV used for palliative purposes.

In spite of convincing and unquestionable proof about the efficacy of NIV in acute exacerbations of chronic obstructive pulmonary disease (AECOPD), an observational survey of clinical practice performed in the UK by RoBERTs et al. [4] demonstrated surprising results. The audit comprised a large group of 9716 patients from 232 units. The results raised significant concerns about the standard of medical management of AECOPD patients. One-third of all eligible patients did not receive NIV, while $11 \%$ of those with metabolic acidosis did. Only 5\% of all acidotic patients received invasive mechanical ventilation [4]. However, the most striking data showed that mortality was significantly higher in patients treated with NIV than in patients who did not receive NIV with the same level of respiratory acidosis. Unfortunately, data on how many of NIV patients were managed in high-dependency units (HDUs) or intensive care unit (ICUs) were lacking. Even taking into account that the study was not a randomised controlled trial (RCT) and there could be other factors apart from $\mathrm{pH}$ which could determine patients' prognosis, it

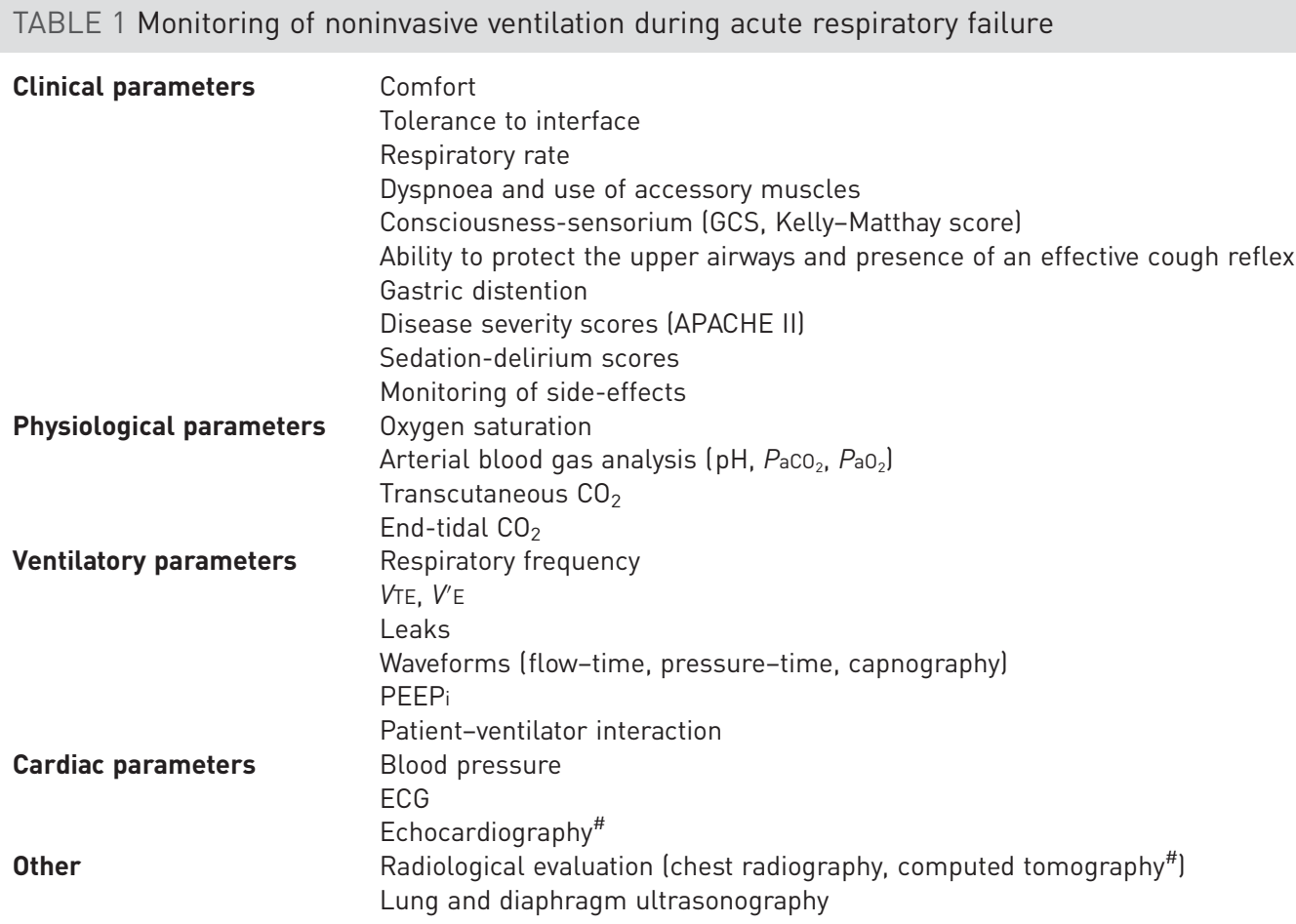

GCS: Glasgow coma scale; APACHE II: Acute Physiology and Chronic Health Evaluation II score; $P_{a C_{2}}$ : arterial carbon dioxide tension; $\mathrm{PaO}_{2}$ : arterial oxygen tension; $\mathrm{CO}_{2}$ : carbon dioxide; VTE: expiratory tidal volume; V'E minute ventilation; PEEPi: intrinsic positive end-expiratory pressure. \#: only in selected patients when needed. 
demonstrated clearly that NIV achieves its benefits only in cases of appropriate administration, adequate monitoring and predicted escalation pathway in cases of deterioration [4]. Otherwise, NIV may be harmful, because it can postpone or waive the decision about effective treatment, e.g. invasive ventilation [5].

It is important to stress that there is a "learning curve" impact on the success of NIV [6], so adequate staff training should be implemented and regularly checked [7].

The aim of this article is to review how to monitor NIV in patients hospitalised for ARF and who have no preset limitations on life-sustaining treatments.

\section{Levels of care and monitoring in patients receiving NIV}

In most countries, there are three levels of facilities: the ICU, a respiratory intermediate care unit with particular expertise in NIV (respiratory HDU (RHDU)) and the respiratory general ward (table 2) [8]. The efficacy of NIV has been proven in each of these three locations [9].

The use of NIV in the ICU is supported by the strongest scientific evidence. Most of the controlled studies that demonstrated that treatment with NIV decreases mortality were performed in ICUs [10-13]. Nonetheless, the ICU should be recommended as a location for NIV treatment only for severely ill patients, with a high risk of NIV failure: severe respiratory acidosis ( $\mathrm{pH}<7.20-7.25)$ [14], significantly impaired level of consciousness and multi-organ failure [15]. We would like to stress that the decision

\section{TABLE 2 Levels of monitoring of patients receiving noninvasive ventilation (NIV)}

\begin{tabular}{|c|c|c|c|}
\hline & General ward & HDU & ICU \\
\hline $\mathrm{pH}[10,14,28]$ & $7.35-7.30$ & $7.30-7.20$ & $<7.20$ \\
\hline \multicolumn{4}{|l|}{ Respiratory rate breaths $\cdot \min ^{-1}$} \\
\hline Restrictive disorders & $<30$ & $30-35$ & $>35$ \\
\hline Obstructive disorders & $<25$ & $25-35$ & $>35$ \\
\hline \multicolumn{4}{|l|}{ Level of consciousness } \\
\hline Failure of other organs & No & Debatable & Yes \\
\hline Oxygenation & $\begin{array}{l}\text { Corrected with } \\
\text { low-flow oxygen } \\
\text { (nasal prongs) }\end{array}$ & $\begin{array}{c}\text { Corrected with high-flow oxygen } \\
\text { (Venturi mask or nonrebreathing } \\
\text { mask) }\end{array}$ & $\begin{array}{l}\text { Not corrected with } \\
\text { high-flow oxygen }\end{array}$ \\
\hline $\mathrm{PaO}_{2} / \mathrm{FlO}_{2}$ ratio [122-124] & $>150$ & $<150$ & $<100$ \\
\hline \multicolumn{4}{|l|}{ Monitoring } \\
\hline Blood pressure & Occasional & Occasional & Continuous \\
\hline Heart rate $\#$ & Occasional & Continuous & Continuous \\
\hline Respiratory rate & Occasional & Continuous & Continuous \\
\hline Level of consciousness & Not necessary & Frequent & Frequent \\
\hline \multicolumn{4}{|l|}{ Gas exchange } \\
\hline $\mathrm{SpO}_{2}$ & Every $2-4 \mathrm{~h}$ & Continuous & Continuous \\
\hline Arterial blood gas analysis" & Every $8 \mathrm{~h}$ & Every $2-4 \mathrm{~h}$ & $\begin{array}{l}\text { Frequent by } \\
\text { arterial line }\end{array}$ \\
\hline $\mathrm{PtcCO}_{2}$ & Not necessary & Indicated & Indicated \\
\hline \multicolumn{4}{|l|}{ Ventilator parameters } \\
\hline Leak, VTE, I:E, V'E & Every $2-4 \mathrm{~h}$ & Every $1 \mathrm{~h}$ & Continuous \\
\hline Patient-ventilator asynchrony & Occasional & Frequent & Frequent \\
\hline
\end{tabular}

Note that most of the values are not scientifically confirmed and cannot be understood as strict cut-off points, but rather as helpful tips to manage a patient receiving NIV. HDU: high-dependency unit; ICU: intensive care unit; GCS: Glasgow coma scale; $P \mathrm{a}_{2}$ : arterial oxygen tension; $\mathrm{FlO}_{2}$ : inspiratory oxygen fraction; $\mathrm{SpO}_{2}$ : arterial oxygen saturation measured by pulse oximetry; $\mathrm{PtcO}_{2}$ : transcutaneous carbon dioxide tension; VTE: expiratory tidal volume; I:E: inspiration to expiration ratio; $V^{\prime} \mathrm{E}$ : minute ventilation. ${ }^{\#}$ : by ECG monitoring; ${ }^{\text {П: }}$ first assessment should be made within first hour of NIV, then depending on patient's clinical state and always in cases of deterioration; frequency should be maintained until improvement and stabilisation of respiratory insufficiency. 
about admission to ICU should not be based on a single factor such as $\mathrm{pH}$ or ratio of $\mathrm{PaO}_{2}$ to inspiratory oxygen fraction $\left(\mathrm{FIO}_{2}\right)$, but multiple parameters should be taken into account: general condition (e.g. Acute Physiology and Chronic Health Evaluation (APACHE) II score), physiological parameters (respiratory rate and level of consciousness) and the patient's progress over time and presence of comorbidities $[15,16]$.

The limited number of available beds in the ICU is the main factor precluding the admission of patients with less severe conditions. As shown by IAPICHINo et al. [17], intensivists are careful not to admit lesssevere patients or patients with low performance status to the ICU, and they tend to admit surgical patients more readily than medical ones. Moreover, the treatment of patients with moderate illness in the ICU could even be harmful, both psychologically (patients find ICU stays very distressing) [18, 19], and due to other ICU-related factors, for example invasive procedures are more likely to be undertaken [20] by ICU staff, and the likelihood of complications, mostly ICU-acquired infections [21]. Apart from these concerns, the ICU setting provides the following advantages over the HDU: 1) high levels of nurse staffing; 2) access to invasive or highly specialised monitoring, such as pulmonary artery catheterisation and determination of central venous oxygen saturation, invasive arterial blood pressure and transdiaphragmatic pressure; 3) facilities for prompt escalation of therapy (e.g. invasive ventilation) and treatment of other organ failures.

The RHDU is a relatively modern unit, designed to care for acute patients who do not meet the indications for admission to the ICU. The levels of care, including monitoring and management of patients are hugely variable between different RHDUs. According to need, type and structure of RHDU inside the hospital, different opportunities are provided, both for monitoring and interventions [22]. Monitoring and managing more severely ill acute patients at higher risk of NIV failure (i.e. severe hypoxaemia) is feasible only in the higher levels of RHDU (respiratory ICU), where NIV could be converted promptly to invasive ventilation, and other capabilities of complex interventions are available, such as invasive monitoring, extracorporeal carbon dioxide $\left(\mathrm{CO}_{2}\right)$ removal, renal support, etc. At the other end of the spectrum, some RHDUs are "less invasive" monitoring units (respiratory monitoring units) for less sick patients who only have respiratory failure. The foremost advantage of RHDUs consists of staff highly experienced in NIV techniques. Organisation of the RHDU allows for continuous monitoring of vital parameters and assessment of the efficacy of NIV support. The data also suggest that treatment in RHDUs is cost effective [23]. Monitoring on the RHDU should include noninvasive methods permitting continuous assessment of respiratory and cardiac functions and frequent assessment of vital signs, with the main aim of early detection of failure of NIV. Despite a shortage of strong evidence, the most promising method of monitoring the efficiency of gas exchange seems to be continuous monitoring of $\mathrm{CO}_{2}$ tension and arterial oxygen saturation $\left(\mathrm{SaO}_{2}\right)$, enhanced by periodical assessment of arterial blood gas (ABG) analysis [24].

The general ward is not considered as a location for NIV in every country, which is a rational approach. There are a few studies describing use of NIV in the general ward, giving promising results [25-27]. The most substantial of them, a multicentre RCT performed by PLANT et al. [28] proved that patients with AECOPD and mild acidosis ( $\mathrm{pH} 7.30-7.35)$ can be treated on the general ward safely and with success in terms of decreasing the rate of intubation and mortality. The main reason for the need to apply NIV on general wards is a shortage of beds within the RHDU or simply a lack of such a facility within a hospital. Thus, on one hand NIV in a general ward setting is justified by the positive results of a RCT in terms of improved survival [28], but on the other hand its use must be adequately monitored and escalation of treatment and transfer to a facility with higher level of monitoring should be always kept in mind, because the outcome for patients with a $\mathrm{pH}<7.30$ was less satisfactory [28]. Moreover, most of the studies included patients with AECOPD. Convincing evidence of the use of NIV in general ward with other diagnoses is lacking. Moreover, in one observational study, a non-COPD diagnosis was found to be a risk factor of NIV failure [27]. In particular, patients with de novo acute hypoxaemic respiratory failure should not be treated in general wards, where the lack of monitoring could lead to a delayed detection of NIV failure, prolonged time to intubation and, eventually, increased mortality. There is limited evidence that high-flow nasal oxygen can be a safe alternative in patients with hypoxaemic ARF [29].

There are no direct evidence-based data showing the best way of monitoring NIV. Similarly, there are no trials comparing different levels of monitoring, which could give us evidence-based arguments to use in clinical practice. Apparently, the monitoring of NIV is not an issue that could be clearly standardised under the rigid evaluation of RCTs. The rational approach to optimally adjust the level of monitoring may be to look for risk factors of NIV failure in the published RCTs. The more risk factors present, the higher the level of monitoring needed [9]. However, in most studies, monitoring was described very briefly, usually concentrating on periodic clinical assessment and ABG analysis. BROCHARD et al. [10] conducted their study in the ICU setting (mean $\mathrm{pH}$ of the cohort 7.27-7.28) and as a follow-up reported only checking for respiratory rate, encephalopathy and ABGs 1,3 and $12 \mathrm{~h}$ after starting NIV. In the same way, PLANT et al. [28], who treated patients in general wards (mean $\mathrm{pH}$ 7.31-7.32) made their assessment after 
the 1st and 4th hour of NIV. In both studies, the significant benefit of using NIV was proven and those two studies became a cornerstone for the positive results of meta-analysis [30]. A study by ConfalONIERI et al. [15] gives important and universal indications for monitoring in different care settings. The authors created specific flow charts of the risk of NIV failure on the basis of the outcome of $>1000$ consecutive patients with acidotic AECOPD admitted to three ICU, six RHDU and five general wards. The probability of NIV failure was influenced by clinical assessment of severity of illness using APACHE II score, neurological impairment using Glasgow coma score (GCS) and respiratory rate. The main factor influencing the outcome was the $\mathrm{pH}$ value. The two flow charts proposed by authors stratified the risk of NIV failure based on data obtained upon admission and after $2 \mathrm{~h}$ of treatment, which stressed the importance of the close follow-up of patients in the very first hours of treatment. In case of a lack of improvement in clinical status and $\mathrm{pH}$, in spite of correct NIV administration, the risk of failure increases significantly.

\section{Clinical parameters to monitor during NIV}

The benefits of NIV depend directly on choosing the right patient and the correct application of the technique. Several clinical parameters such as patient comfort, tolerance of the interface, dyspnoea, respiratory rate and oxygen saturation should be monitored every $30 \mathrm{~min}$ for the first $6-12 \mathrm{~h}$ and then hourly after the initiation of support [31]. Additionally, the consciousness and sensorium of patient, the ability to protect upper airways with an effective cough and the expectoration of secretions are important parameters that should be monitored in a routine basis by the medical staff applying NIV. Other than GCS, the level of consciousness can be evaluated directly using the Kelly-Matthay score and a score of $>3$ may raise the alarm for depressed consciousness and high risk of NIV failure [32]. Some patients with severe dyspnoea may experience agitation. Explaining the technique, asking the patient's preference for the interface and initiation at low pressures followed by stepwise increases may be helpful to overcome agitation; however, mild sedo-analgesia may be beneficial in some patients for symptom relief, improved patient tolerance and compliance $[33,34]$. It is important to remember that the level of sedation should be monitored closely at regular intervals with sedation protocols and scales (Richmond agitation-sedation scale or Ramsay sedation scale) in order to achieve an optimum sedation level in patients receiving NIV. Besides the change in the level of consciousness, delirium may be a problem in some patients. Although delirium is relatively a common problem, particularly in ICU patients, it is underdiagnosed in patients receiving NIV [35]. Delirium is reported to be directly associated with NIV failure and mortality [36-38]. Therefore, daily routine screening of delirium during NIV, using diagnostic aids such as the confusion assessment method or nursing delirium screening scale, should be encouraged [39].

\section{Monitoring of gas exchange}

According to recent British Thoracic Society (BTS)/Intensive Care Society (ICS) guidelines, oxygen saturation should be monitored continuously and arterial $\mathrm{CO}_{2}$ tension $\left(\mathrm{PaCO}_{2}\right)$ and $\mathrm{pH}$ should be monitored intermittently [33].

\section{Pulse oximetry}

Pulse oximetry has become standard practice in monitoring oxygenation during ARF, although its accuracy may depend on the type of oximeter or the patient's haemodynamic status [40].

The plethysmographic waveform is a valuable tool in tracking poor peripheral perfusion, and new models and algorithms have improved performance [41]. The target of arterial oxygen saturation measured by pulse oximetry $\left(\mathrm{S}_{\mathrm{pO}_{2}}\right)$ under NIV should be different in hypercapnic and hypoxaemic patients [33]. In cases of hypercapnic ARF treated with NIV, $\mathrm{SpO}_{2}$ targets should be $88-92 \% . \mathrm{SpO}_{2} / F \mathrm{IO}_{2}$ ratio has been shown to be a good marker of oxygenation and a surrogate of the $\mathrm{PaO}_{2} / \mathrm{FIO}_{2}$ ratio [42].

\section{Transcutaneous $\mathrm{CO}_{2}$}

$\mathrm{PaCO}_{2}$ can be estimated using $\mathrm{ABG}$ analysis, capnography and transcutaneous $\mathrm{CO}_{2}$ measurement. Noninvasive $\mathrm{CO}_{2}$ measurements have become popular in the context of home mechanical ventilation [43].

In addition, transcutaneous $\mathrm{CO}_{2}$ monitoring in the context of ARF has been carefully evaluated [44-47]. Compared to arterial $\mathrm{PaCO}_{2}$ measurements, transcutaneous $\mathrm{CO}_{2}$ monitoring showed high agreement in different timings and disease categories [45, 46, 48], suggesting that it could be very convenient for estimating the ventilatory response to NIV, facilitating proactive (rather than reactive) ventilator titration. In fact, in a study by VAN OPPEN et al. [46], hypothetical clinical decisions based on transcutaneous data alone matched true management on $85 \%$ of 34 occasions. Moreover, subjects requiring NIV for hypercapnic ARF preferred transcutaneous monitoring to ABG measurement [46]. One of the major limitations is that transcutaneous $\mathrm{CO}_{2}$ measurement underestimates $\mathrm{PaCO}_{2}$ levels, especially for those who are severely hypercapnic $[47,49]$. It is important to know that there are differences in accuracy between 
devices [43], and methodological issues may have an influence, for example placing the electrode in the earlobe $[45,46,48-50]$, in the upper chest $[47,51,52]$ or abdomen [44].

German guidelines recommend transcutaneous $\mathrm{CO}_{2}$ monitoring during the initiation of NIV, in combination with frequent $\mathrm{ABG}$ assessment [53]. According to the recent BTS/ICS guideline, transcutaneous $\mathrm{CO}_{2}$ measurement may better facilitate the discontinuation of NIV than continuing with arterial or capillary sampling [33]. Thus, transcutaneous $\mathrm{CO}_{2}$ monitoring could replace frequent $\mathrm{ABG}$ measurements for monitoring patients with ARF undergoing NIV, since it is patient-friendly, feasible, reliable and safe. A synchronous ABG analysis at baseline is recommended to validate levels and may be advisable in cases of higher transcutaneous $\mathrm{CO}_{2}$ values $(\geqslant 60 \mathrm{mmHg})$ [47].

Although the evidence is growing about transcutaneous $\mathrm{CO}_{2}$ monitoring on this setting, the gold standard remains the $\mathrm{PaCO}_{2}$ value. Additionally, acidosis level can only be assessed accurately with ABG analysis.

\section{End-tidal $\mathrm{CO}_{2}$}

The measurement of end-tidal $\mathrm{CO}_{2}\left(\mathrm{ETCO}_{2}\right)$, or capnography, is used more frequently for intubated patients, and it is not as accurate due to the physiological dead space.

In one study, LERMUZEAUX et al. [49] showed that $\mathrm{ETCO}_{2}$ measurement in spontaneously breathing subjects significantly underestimated $\mathrm{PaCO}_{2}$, and to attain a correct value it required active cooperation of the patients in order to obtain a good alveolar plateau. Moreover, SchwARz et al. [54], using an integrated $\mathrm{ETCO}_{2}$ sensor with a ventilator, showed underestimation of $\mathrm{PaCO}_{2}$ values, especially in chronic obstructive pulmonary disease (COPD). For COPD patients, flow limitation, with the consequent incomplete emptying of the lung and poor ventilation/perfusion ratios are the main reasons for the underestimation of $\mathrm{PaCO}_{2}$ in invasively and noninvasively ventilated patients.

\section{$A B G$ analysis}

ABG analysis is the gold standard for monitoring respiratory failure. After the first trial of ventilation, $\mathrm{pH}$ and $\mathrm{PaO}_{2} / \mathrm{FIO}_{2}$ changes have important prognostic value in hypercapnic and hypoxaemic ARF patients, respectively. Furthermore, advantages of ABG measurements include the assessment of additional parameters such as haemoglobin and electrolytes.

Typically, blood samples are taken either via single arterial puncture or an arterial catheter. Some authors suggest subcutaneous anaesthetic infiltration before arterial puncture, because it significantly reduces pain by $>50 \%[55]$.

Arterialised earlobe blood gas analysis is simpler and less painful that ABG; except for patients with severe shock, it compares very well with arterial sampling [56].

ABG measurements should be undertaken at baseline, and 1-2 h after NIV [15]. A positive response to NIV could be considered a decrease of $0.40 \mathrm{kPa}$ (or $3 \mathrm{mmHg}$ ) of $\mathrm{CO}_{2}$ [57] and an increase of $0.03 \mathrm{of} \mathrm{pH}$ [57]. Typically, ABG monitoring should be maintained until normalisation of $\mathrm{pH}$ and $\mathrm{PaCO}_{2}$ is achieved. After discontinuation of NIV, ABG should be repeated in cases of suspected relapse [58].

\section{Monitoring of ventilator parameters}

Although several successful non-ICU RCTs used "simple ventilators" [28], which were not provided with sophisticated monitoring systems, we recommend using ventilators which provide "online" monitoring of respiratory parameters for the treatment of ARF in the hospital environment. Control of the data obtained by the device and describing patient's ventilation status is very useful in the assessment of the efficacy of the ventilation. However, most of the parameters are calculated by the built-in algorithms, therefore not measured directly, and are not free from bias [59]. Accordingly, monitoring of ventilator parameters can have only additional meaning, e.g. to help understand a lack of clinical improvement, but cannot exempt the practitioner from the careful monitoring of patients' clinical status and gas exchange $\left(\mathrm{PaO}_{2}\right.$ and $\left.\mathrm{PaCO}_{2}\right)$.

The ventilatory system features directly affect monitoring, and depending on the type of the device and ventilatory circuit used, different parameters can be followed. We would suggest using devices providing flow and pressure waveforms in real time and other ventilation parameters (leak and inspiratory and expiratory tidal volume (VTI and VTE, respectively), minute ventilation, inspiratory time, respiratory rate and inspiration (I)/expiration (E) ratio) as a numerical data. Ventilators that use a double-limb circuit with an integrated expiratory valve provide sophisticated tools of monitoring of ventilation, including all kinds of respiratory loops and curves and calculation of compliance and resistance. In double-limb circuits, VTE represents alveolar ventilation and the amounts of leaks can be calculated by the difference between $V$ TI and VTE. In single-limb circuits, the mode of exhalation and the position of the flow sensor in relation to the exhalation device have a major influence on respiratory traces [60]. 
Despite the higher level of monitoring therein, ventilators in the ICU are more prone to patient-ventilator asynchrony, mainly auto-triggering, than home devices [61]. This is because NIV is a semi-open system and air leaks are the major cause of asynchrony during the application of NIV with ICU ventilators. This problem can be minimised by the activation of the NIV mode in the ICU ventilator, which activates special algorithm programmes for leakage compensation. A study performed by Doorduin et al. [62] showed that asynchronies are still relatively common both in ICU and NIV-dedicated ventilators and the use of diaphragmatic electrical activity with neurally adjusted ventilatory assist is beneficial for ventilatorpatient interaction. Choosing the right type of interface is critical for the effectiveness of NIV, because many ventilators, whether of the ICU type or NIV-dedicated cannot maintain the set positive end-expiratory pressure (PEEP) and pressure support in the presence of large air leaks [63].

\section{Basic parameters of ventilation}

$V$ TE is the main parameter to monitor as it reflects the patient's alveolar ventilation under NIV. It is either measured directly by a proximal flow sensor in a double-limb circuit system or calculated from the integral of the flow signal with adjustments for unintentional leaks in a single-limb circuit system [64]. Pressure support ventilation, usually called bilevel positive pressure ventilation or spontaneous/timed mode is the most-often used mode of ventilation during NIV [57]. Providing a certain level of inspiratory pressure, a clinician cannot be sure about the obtained tidal volume, which is the result of several physiological variables: resistance of airways, compliance of the lung and chest, the patient's respiratory effort and time of inspiration. Before starting NIV, the desirable VTE should be determined. Usually it is calculated on the basis of ideal body weight and ranges from $6 \mathrm{~mL} \cdot \mathrm{kg}^{-1}$ for neuromuscular and restrictive chest wall disorders to $8-10 \mathrm{~mL} \cdot \mathrm{kg}^{-1}$ in obstructive diseases and obesity [33]. There is evidence that monitoring of the rapid shallow breathing index (RSBI) (respiratory rate divided by VTE in litres) may be a good predictor of NIV success. In a heterogeneous group of patients, BERG et al. [65] demonstrated that RSBI $>105$ is associated with a significant increase in NIV failure and mortality. However, clinicians must be aware of the limitations of the parameters displayed by the ventilator. For example, when a significant number of unrewarded efforts exist, the ventilator respiratory rate will be lower than patient respiratory rate. CONTAL et al. [59] demonstrated that VTE reported by ventilator software may differ significantly from the real values. Depending on the device, VTE was underestimated by $66-263 \mathrm{~mL}$ and the difference was correlated with higher inspiratory pressure [66].

Air leakage is an inevitable consequence of NIV, and efficacy of the noninvasive respiratory support largely depends on the minimisation of the leaks. Devices used for NIV must inform continuously about the level of leakage in order to optimise the mask adherence. The staff must be aware of the ideal leakage that could be obtained in the device, interface and circuit used, whether or not the intentional leak is calculated together with unintentional leaks. Moreover, type of circuit and expiratory valve may influence on leak assessment [67]. Bilevel ventilators use a single circuit either with a calibrated intentional leak (vented circuit) or an expiratory valve (nonvented circuit). The problem with the latter is they only provide $V$ TI and cannot measure VTE, and therefore patient's real VTI, during leaks. In vented circuits, VTE is estimated during a constant leak; however, these devices may perform less well when the amount of leak varies. Estimation of leaks performed by ventilator software is less precise when the leak increases [59].

I/E ratio is an important variable which informs about the efficacy of emptying the lungs of air and about the risk of hyperinflation. In obstructive disorders, I/E should be maintained at the lowest possible range, while in restrictive disorders the ratio can be higher, which means that inspiratory and expiratory times can be close [33].

\section{Intrinsic positive end-expiratory pressure}

The presence of intrinsic PEEP (PEEPi) is a typical phenomenon in obstructive airways diseases. PEEPi is present in variable degrees in moderate to severe COPD patients and the degree of hyperinflation increases during exacerbations. Usually, it ranges between 4.6 and $13.6 \mathrm{cmH}_{2} \mathrm{O}$ [68]. PEEPi causes dynamic hyperinflation (end-expiratory lung volumes exceeding functional residual capacity), decreased respiratory system compliance and increased respiratory workload. As the inspiratory muscles start to contract, they must first overcome the threshold which is PEEPi before inspiratory flow can start. Ventilatory triggering and inspiratory flow only starts after PEEPi is counterbalanced. Therefore, an external PEEP applied with the ventilator, which is equivalant to $\mathrm{PEEP}_{\mathrm{i}}$, decreases the work of breathing and reduces ineffective trigger in these patients.

Assessment of PEEPi should be undertaken during mechanical ventilation and the effort to optimally adjust expiratory pressure should be performed in order to reduce work of breathing, improve patientventilator synchrony and increase VTE. The degree of PEEPi can be measured invasively using an oesophageal pressure transducer. Dynamic PEEPi is measured as the negative deflection of oesophageal 
a)
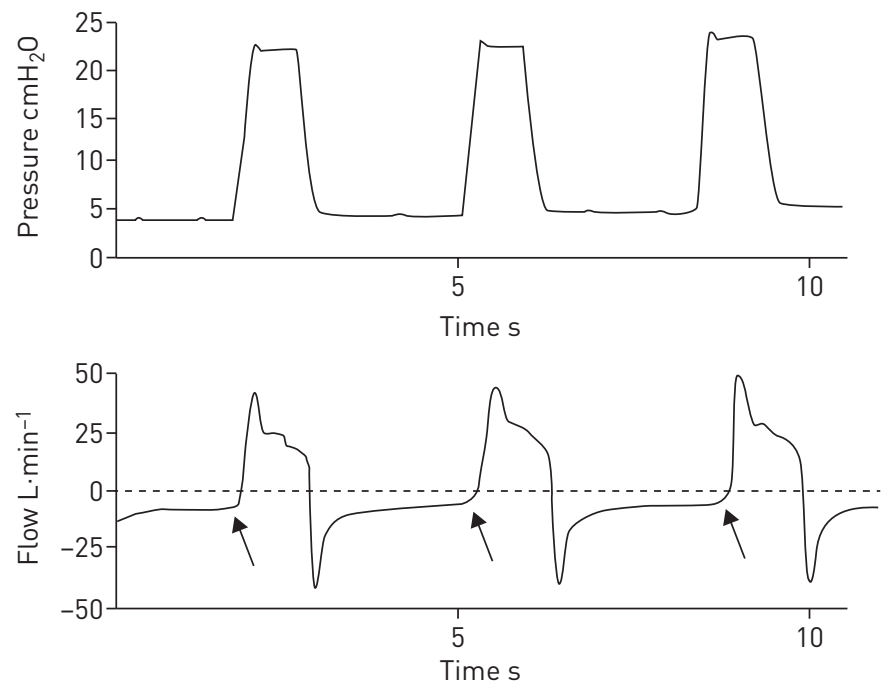

b)
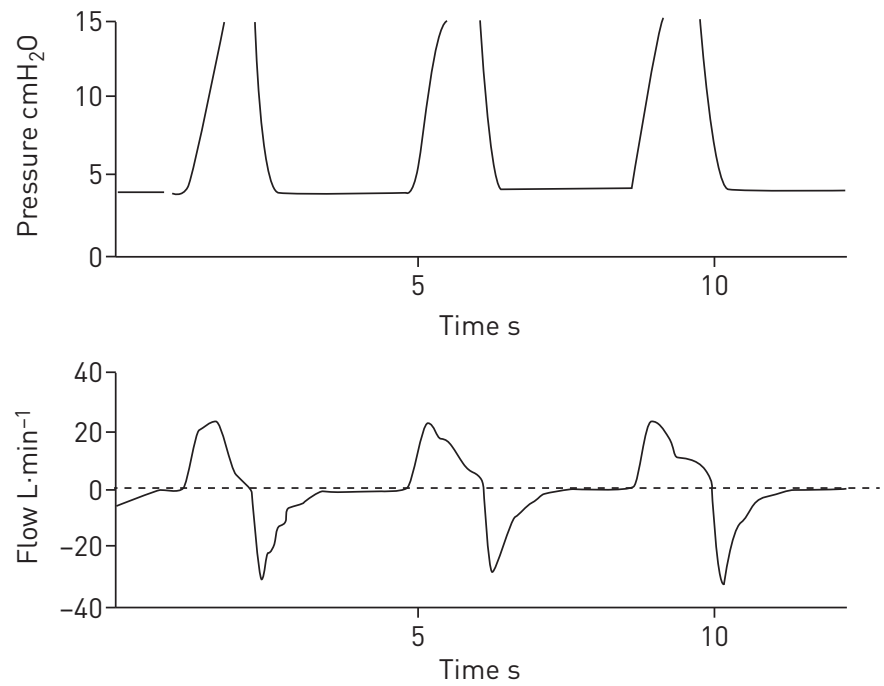

FIGURE 1 a) Pressure-time and b) flow-time waveforms in the panel of ventilator Astral 150 (ResMed, Bella Vista, Australia). a) The expiratory flow curve does not reach the zero-flow line when the inspiration starts (arrows), meaning that the expiratory time was not sufficient for lung emptying, providing proof of the presence of intrinsic positive end-expiratory pressure (PEEPi). b) The expiratory flow curve reaches the zero-flow before the inspiration starts, meaning that the expiratory time was sufficient for lung emptying. There is no PEEPi.

pressure from the onset of inspiratory effort to the point of zero flow at end-expiration. The disadvantages are the requirement for special equipment and experienced staff. Most modern ICU ventilators can measure PEEPi occluding the expiratory port of the ventilator at the end of expiration [69]; however, it refers only to invasive ventilation and requires sedation and neuromuscular blockage. In the course of NIV, the presence and the degree of PEEPi can be identified by inspection of the expiratory flow-time curve (figure 1).

\section{Patient-ventilator interaction}

Patient-ventilator synchronisation is an important issue which can influence the efficacy and success of NIV [70, 71]. The most common phenomenon is ineffective triggering (patient effort is not recognised by the ventilator; may be secondary to high PEEPi or inappropriate inspiratory trigger sensitivity), followed by auto-triggering (delivery of preset pressure in the absence of patient effort) and double-triggering (consecutive delivery of two preset pressure support events within an interval of less than half of the mean inspiratory time due to patient's continued effort) [72, 73]. Other types of asynchrony consist of late cycling (mechanical inspiratory time $>$ neural inspiratory time), premature cycling (mechanical inspiratory time $<$ neural inspiratory time) and flow asynchrony (inappropriate rate of pressurisation to inspiratory positive airway pressure (IPAP)) [71, 74]. Patient-ventilator asynchrony is a frequent phenomenon during NIV. Substantial levels of asynchrony, defined as $>10 \%$ of all patient's respiratory efforts, occur $>40 \%$ of patients [74]. The number of asynchronies is correlated with the magnitude of leak and higher pressure support [74]. It was shown that high number of asynchronies is associated with decreased patient comfort, and possibly tolerance to NIV. Asynchronies are not shown to have any influence on gas exchange or any other clinical parameters.

The gold standard for measuring patient-ventilator asynchrony is recording of the electrical activity of the diaphragm and pressure changes in the oesophagus, which requires sophisticated equipment and is invasive. Otherwise, asynchrony can be detected by observation of patient and ventilator rhythm of respiration. The most practical method should be analysis of the pressure and flow waveforms [75], demonstrated in figure 2. Modern portable ventilators allow for online monitoring of pressure and flow waveforms, which make them an appropriate tool of ventilation in a hospital environment. However, clinicians must be aware that observation of respiratory waveforms is not the ideal method of detecting of asynchrony: the patient's effort may not change the flow-time or pressure-time curves, and other factors may influence them, e.g. airway secretions or cardiac oscillations [71]. In a study by YounEs et al. [76], $20 \%$ of ineffective efforts were not detected by waveform analysis.

\section{Respiratory waveforms}

Observation of pressure-time and flow-time waveforms during NIV can be useful not only for detection of patient-ventilator asynchrony, but also other additional information about the quality of the ventilation: 

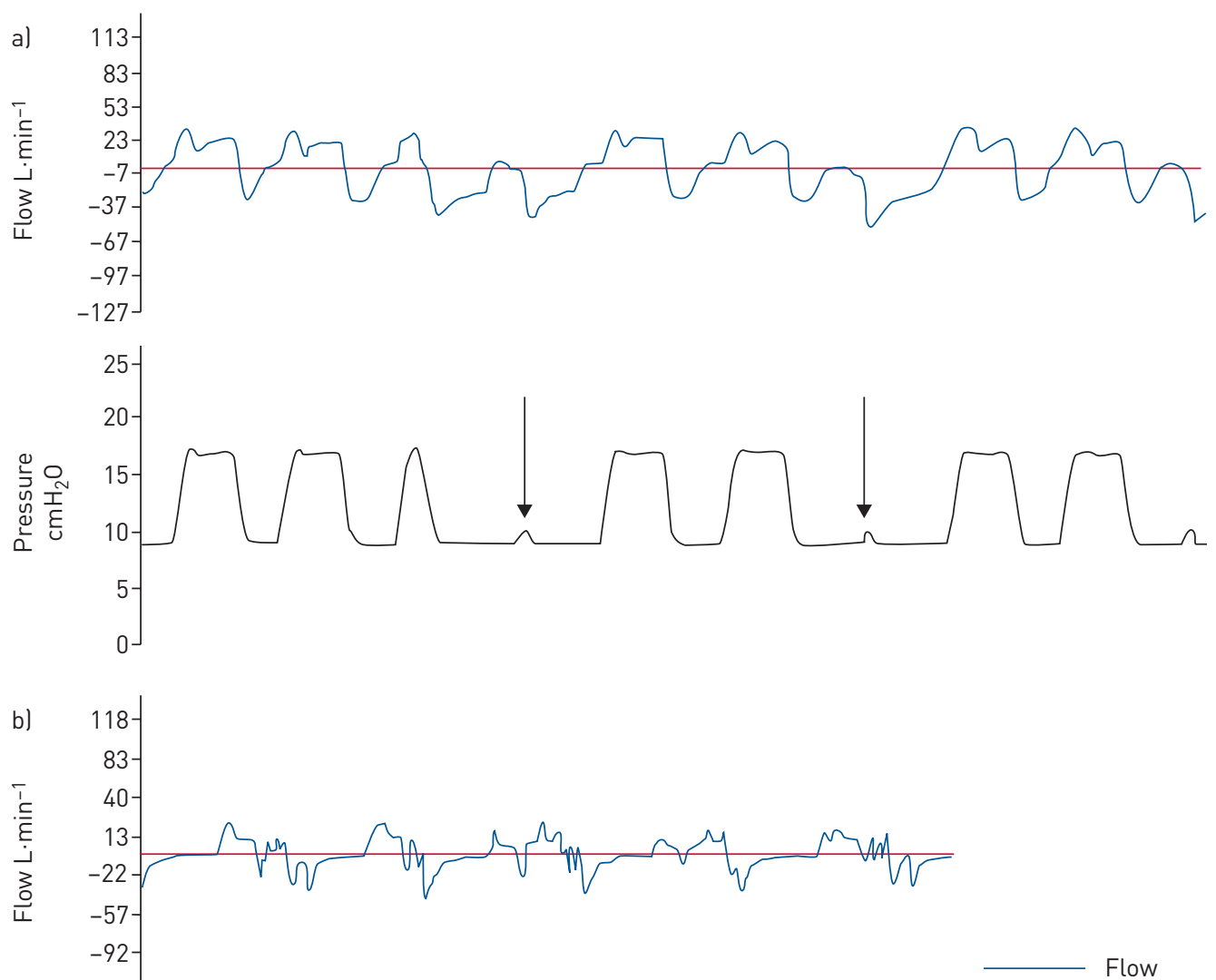

$-127$

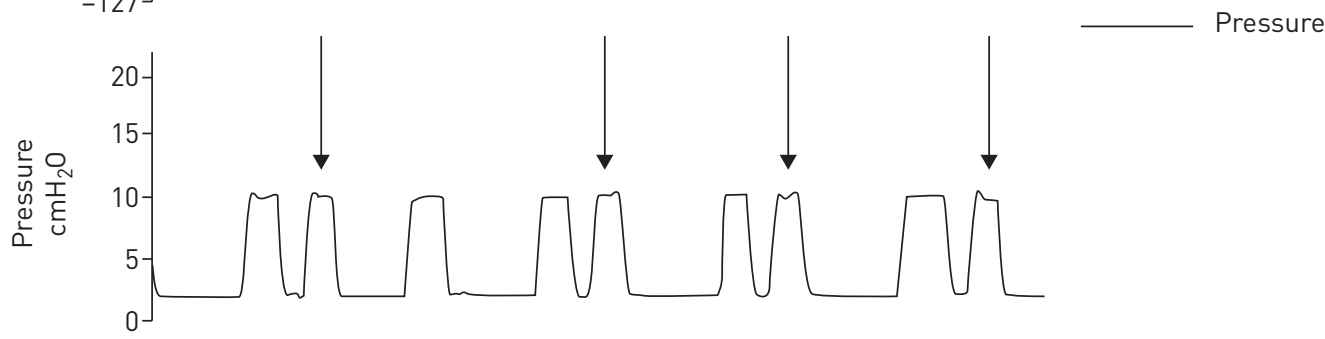

FIGURE 2 Examples of patient-ventilator asynchrony (arrows) revealed in pressure and flow waveforms (data from the software ResScan version 5.6.0.9419). a) Ineffective effort; b) double triggering.

magnitude of leaks, obstruction of airways and I/E ratio. The visualisation of these phenomena makes them easier to spot and to react adequately in terms of titration of the settings of the ventilator. In a multicentre RCT on a cohort of patients with AECOPD, DI MARCO et al. [77] showed that titration of ventilator settings on the basis of analysis of respiratory waveforms in real time resulted in more rapid improvement in $\mathrm{pH}$ and $\mathrm{PaCO}_{2}$ and better tolerance of ventilation by patients.

\section{Sleep studies}

A patient with ARF is usually agitated and vigilant when starting NIV. However, in case of hypercapic coma or in the later phase of treatment, when the patient's condition has improved, ventilation is performed mainly during sleep, when the physiological parameters change and may interfere with the efficacy of ventilation. These disturbances, if not very significant, may be overlooked by nursing staff. Thus, the analysis of the memory of a ventilator with the use of the adequate software can be very useful. It allows for the analysis of overnight ventilation, practically breath by breath, and can reveal events such as excessive leaks, reduction in flow and even desaturations, if pulse oximetry is integrated with the ventilator. As far as we know, there are no data demonstrating clinical benefits of such an approach. However, we recommend the analysis of the ventilator software data after a night of NIV.

Although the acute setting is not an optimal timing for assessment of sleep, Roche CAmpo et al. [37] performed an interesting study assessing sleep disturbances with the use of 17-h polysomnography 
performed 2-4 days after starting NIV for hypercapnic ARF. The authors found that sleep disturbances (abnormal electroencephalographic pattern, greater circadian sleep-cycle disruption and less rapid eye movement sleep) were associated with late NIV failure. The practical significance of this finding is unclear; however, this observation undoubtedly broadens the spectrum of the possibility of monitoring patients under NIV. In spite of this interesting study, it seems that sleep studies could be of help mostly in the recovery phase of ARF, especially for detection of breathing-related sleep disorders and making decisions about chronic treatment.

\section{Monitoring of cardiac function under NIV}

Clinician applying NIV in order to reinforce the ventilatory pump and improve gas exchange must be aware of its effects on the functioning of the cardiovascular system. These effects must be assessed continuously or periodically, to reveal potential side-effects and manage them adequately, as the improvement of respiratory function can be associated with the impairment of cardiac function. Positive pressures are very effective in decreasing $\mathrm{PaCO}_{2}$, but simultaneously may considerably decrease cardiac output and oxygen delivery to tissues [78].

Positive pressures applied during NIV, in contrast to spontaneous breathing, produce positive intrathoracic pressure (ITP) throughout the respiratory cycle. The cardiovascular consequences of the increased ITP are as follows. 1) Decrease in venous return of right ventricle, which decreases right ventricle preload; 2) increase in pulmonary vascular resistance, which increases right ventricle afterload; 3) increase in central venous pressure; 4) decrease in left ventricle afterload due to decrease in systemic blood pressure; and 5) decrease in left ventricle preload, which decreases left ventricle ejection.

Clearly, some effects may be deleterious, while others are beneficial. Because the level of cardiac output depends mainly on preload, the general effect of NIV will be a decrease in cardiac output. In a cohort of stable COPD patients, ventilation with a mean pressure support of $18 \mathrm{cmH}_{2} \mathrm{O}$ reduced cardiac output by $16 \%$, while pressure of $24 \mathrm{cmH}_{2} \mathrm{O}$ reduced it by $24 \%$ [79]. Application of continuous positive airway pressure $\geqslant 15 \mathrm{cmH}_{2} \mathrm{O}$ in healthy subjects reduced cardiac output by $20-30 \%$ [80]. In patients with AECOPD treated with average pressures, expiratory positive airway pressure $3 \mathrm{cmH}_{2} \mathrm{O}$ and IPAP $12 \mathrm{cmH}_{2} \mathrm{O}$, cardiac output and oxygen delivery were decreased by $13 \%$ and $8 \%$, respectively [81].

The overall consequence of NIV mostly depends on the underlying cardiovascular conditions. In patients with hypovolaemia or restrictive cardiomyopathy, a compensatory sympathetic response may develop: tachycardia, vasoconstriction, oliguria and retention of water and sodium chloride [82], while in patients with congestive heart failure with fluid overload and hypertension, ITP may improve cardiac function.

\section{Electrocardiography}

12-lead ECG should be performed in all patients with ARF, irrespective of the history of cardiac disorders. Then, an ECG trace should be monitored continuously in all patients treated in the HDU or ICU. The monitoring should be continued until constant improvement is obtained. BTS/ICS guidelines recommend monitoring ECGs in all patients with tachycardia $>120$ beats $\mathrm{min}^{-1}$, dysrhythmias or possible cardiomyopathy [33].

\section{Blood pressure}

Blood pressure is one of the vital signs and should be systematically assessed throughout the treatment with NIV. Hypotension (systolic blood pressure $<90 \mathrm{mmHg}$ ) is considered to be a relative contraindication to NIV by some authors [83], particularly as a result of arrhythmia [33]. However, the impact of NIV on the systemic blood pressure is less significant than that of invasive ventilation. The aim of the measurement of blood pressure is not only the assessment of the underlying function of cardiovascular system, but also the effect of the application of NIV. Thus, monitoring in the first hour of treatment is strongly advisable. Since there are no evidence-based data, the frequency of measurement is left to the discretion and experience of the clinician. NAVA and HILL [31] propose monitoring vital signs every $30 \mathrm{~min}$ within first $6-12 \mathrm{~h}$ of treatment. CAIRONI et al. [84] suggest taking measurements every 15 min during the first hour, then every $30 \mathrm{~min}$ in the second and third hours and then hourly for the next $8 \mathrm{~h}$. Apparently, there cannot be a routine scheme for every patient and the frequency of assessment has to be adjusted to the patient's condition and ventilation settings (pressure levels).

\section{Echocardiography}

Echocardiography is a useful, noninvasive and easy to perform bedside diagnostic tool. Optimally, it should be performed at the beginning of ventilation, particularly in patients with known or suspected underlying heart disease. Otherwise, echocardiography should be performed when disturbances of cardiovascular system occur in the course of treatment. However, the technical quality of the 
echocardiographic visualisation can be significantly limited due to pathologies frequently present in patients with hypercapnic respiratory failure: emphysema, obesity and kyphoscoliosis.

\section{Other diagnostic and monitoring tests for the respiratory system Radiologic evaluation}

Chest radiography is a routine test for the diagnostic work-up of patients requiring NIV. Aetiological findings include hyperinflation and flatting of diaphragm in AECOPD, interstitial infiltrates in pulmonary oedema, pneumonic consolidation, atelectasis, diffuse alveolar/interstitial infiltrates in acute respiratory distress syndrome and other interstitial lung diseases and pleural effusion.

Computed tomography (CT) of the chest gives more information for the differential diagnosis of the reason for ARF. CT may have good diagnostic accuracy in patients with pneumonia, pulmonary embolism and acute exacerbation of idiopathic pulmonary fibrosis [85].

\section{Lung ultrasonography}

Although ultrasound has been in the field for many years, lung ultrasound has only become very popular within the last decade and now is accepted as an important tool for diagnosis and therapeutic management of critically ill patients [86]. The advantages of ultrasound over other imaging modalities include portability, which is particularly advantageous in the HDU/ICU setting, relatively low cost and absence of contraindications. It is a noninvasive and radiation-free procedure, which can be performed quickly at the bedside in all patients and enables a dynamic assessment of lungs, diaphragm and pleura. The only issue that may limit these advantages is the requirement of expertise in performing the technique. Lung ultrasound yields diagnoses for diaphragmatic dysfunction, parenchymal lung diseases and pleural space pathologies, which may give important clues for the management of patients requiring mechanical ventilation [87-89].

\section{Evaluation of diaphragmatic function}

The diaphragm is the primary muscle of ventilation. Diaphragm function is an important determinant of successful liberation from ventilation and recovery from critical illness. Diaphragm ultrasound is a useful tool to detect diaphragmatic dysfunction, to assess atrophy and to monitor respiratory workload in mechanically ventilated patients [90-92]. During ultrasonographic evaluation of the diaphragm, there are two important parameters: measurement of diaphragmatic movement, defined as diaphragmatic excursion, and measurement of diaphragm thickness (Tdi) during end-expiration. In addition, measuring the change in the thickness during respiratory cycle (thickening fraction (TFdi)) has been used to assess work of breathing and respiratory effort. TFdi is defined as the percentage change in diaphragm thickness between end-expiration and end-inspiration and is calculated by the following formula:

$$
\text { (end-inspiratory Tdi - end-expiratory Tdi)/end-expiratory Tdi } \times 100
$$

It has been shown that the thickness of the right hemidiaphragm can be feasibly and reproducibly measured in the zone of apposition in mechanically ventilated patients [93]. Tidal diaphragm thickening during inspiration indirectly shows inspiratory effort and can be used as a valid tool to identify diaphragm dysfunction. In a recent study, performed by ANTENORA et al. [94], it was shown that severe dysfunction of the diaphragm occurs in almost a quarter of patients with AECOPD admitted to the ICU and diaphragmatic dysfunction was correlated with NIV failure, prolonged mechanical ventilation and need for tracheostomy. The same group showed that diaphragm thickness significantly correlates with global respiratory alterations in amyotrophic lateral sclerosis patients [95]. TFdi has been shown not only to estimate respiratory muscle workload during NIV, but also to predict extubation failure or success during a spontaneous breathing trial in invasively ventilated patients [90]. Moreover, TFdi is well correlated with increasing levels of pressure support during NIV [96]. It has been suggested that titrating ventilatory support with ultrasound to maintain adequate levels of inspiratory effort is helpful for the prevention of changes in diaphragm configuration during mechanical ventilation [97].

Diaphragmatic motion and the magnitude of excursion measured by M-mode ultrasound may be used to assess the function of diaphragm. It should be noted that excursion as an index of diaphragmatic function should be limited to patients breathing spontaneously. Limited excursion of the diaphragm in patients with COPD correlates with the degree of airway obstruction and $\mathrm{PaCO}_{2}$ levels $[98,99]$. However, these findings are not supported in patients receiving mechanical ventilatory assistance. UMBreLLo et al. [91] showed that diaphragm excursion is not correlated to any index of muscle effort under varying levels of muscle loading during assisted ventilation. Ultrasound seems to be a promising technique for evaluating 
diaphragmatic function and titrating the ventilatory support; however, more studies are needed to understand its role during NIV application.

\section{Evaluation of lung parenchyma and pleural space}

Lung parenchyma ultrasonography has been identified as a helpful tool in the assessment of aeration, congestion and consolidation. It is considered as a method of tracking dynamic changes in pulmonary congestion with a higher sensitivity and specificity than clinical examination and chest radiography and is well correlated with invasive monitoring $[100,101]$. Ultrasound is proven to be the best method for both diagnostic and therapeutic options for pleural space disorders, e.g. pneumothorax and pleural effusions. It is superior to chest radiography in the detection of pneumothorax with a sensitivity of $77 \%$ and specificity of $98 \%$ [102]. In addition, ultrasound may be a better and more accurate tool for occult pneumothorax and monitoring progression of pneumothorax during positive pressure ventilation [103, 104].

\section{Fibreoptic bronchoscopy}

Patients treated for ARF in the ICU often require fibreoptic bronchoscopy (FOB) for diagnostic or therapeutic purposes. The most common indications for FOB during NIV are removal of the mucus plugs from the tracheobronchial tree and microbiological evaluation of pulmonary infections, especially in the immunocompromised host. FOB for clearing airways helps to improve ventilation and oxygen exchange, thereby avoiding intubation [105]. In special circumstances FOB with or without transbronchial biopsy may be needed for differential diagnosis such as cytopathologic analysis in diffuse interstitial infiltrates $[106,107]$. Other indications are atelectasis, possibility of lung cancer and assessment of the tracheobronchial tree for tracheobronchial rupture/fistula after surgery or chest trauma.

While FOB is generally considered a safe intervention, the risk-to-benefit ratio must be considered in detail in patients with ARF, because of the possibility of worsening of gas exchange. For that reason, close ABG analysis should be performed and adjustments in NIV settings including $\mathrm{FIO}_{2}$ should be considered for the maintenance of adequate gas exchange. Other FOB-related complications such as gastric distention, aspiration, fever, pneumothorax and new worsening of pre-existing or new-onset cardiac arrhythmia can be seen, which are seldom clinically important $[105,107]$. However, it is crucial to perform FOB with expert staff in the ICU under close monitoring, as there may be need for emergency intubation or invasive mechanical ventilation. The availability of other interventions for severe cardiopulmonary emergencies should be guaranteed.

\section{Monitoring side-effects}

Side-effects related to NIV are usually mild, but they may have a negative influence on NIV success. Minor complications are generally associated with either the interface or ventilatory circuit problems and can be managed easily with appropriate interventions. In contrast, serious side-effects are relatively rare, but if they occur, discontinuation of NIV support should be considered.

\section{Minor side-effects}

Interface-related side-effects

Patient compliance, and therefore NIV success, is greatly dependent on the interface. The oronasal mask is the most frequently used interface type, because of the possibility of mouth breathing due to respiratory distress in ARF. An ideal mask must be comfortable, must fit the face well without any excessive tightness and pressure on the skin. One of the most common problems with the use of oronasal masks is pressure-related skin erythema and damage, which occur in $20-34 \%$ of patients [108]. However, loose positioning of mask may cause excessive unintentional air leaks, which are a well-known cause of NIV failure. Unintentional leaks may reduce the efficiency of NIV support, reduce patient tolerance, cause awakenings and sleep fragmentation and increase patient-ventilator asynchrony $[109,110]$. NIV delivered by helmet could be a safe alternative in patients intolerant to the oronasal mask [111, 112]; however, ineffective triggering, patient asynchrony and high flow for $\mathrm{CO}_{2}$ clearance may cause problems in some patients $[113,114]$. Recent studies have shown that compared to the standard helmet, the use of a new design of helmet (with less internal volume) may reduce asynchronies and improve $\mathrm{CO}_{2}$ clearance $[111,115]$. A total face mask may be considered, and is usually well tolerated in ARF [116]. Offering a range of masks and mask sizes is the best approach to minimise interface-related side-effects. Meanwhile, as each interface has its own characteristics, evaluation is needed to adjust pressure and trigger settings and check possibility of rebreathing. Staff involved in delivering NIV need training and experience of using each one of them.

Other interface-related minor side-effects are skin rash, nasal congestion and dryness and eye and ear irritation, which can be managed easily by changing the interface or other basic interventions such as use of topical ointments, nasal steroids, saline or decongestant drops. 
Gastric distention

Aerophagia is a relatively common problem and may increase the risk of vomiting and aspiration while undergoing NIV [108, 117]. Patients should be monitored for the risk of gastric distention, and decompression of gastric air using a nasogastric tube should be considered as a preventive measure in severe cases who have increasing abdominal distention, persistent nausea and vomiting. If vomiting occurs, the mask should be removed immediately and cough should be encouraged for airway clearance.

\section{Secretion clearance}

The presence of copious secretions increases the risk of NIV failure. Ideally, conscious patients should have the ability to clear their airways by effective cough; however, patients with altered mental status may need to be encouraged to cough. Physiotherapy techniques and tracheal aspirations may be helpful in some patients. In addition, mechanical insufflation-exsufflation should be used in patients who have ineffective cough and sputum retention due to neuromuscular disease [33].

\section{Serious side-effects}

Pneumonia

The incidence of nosocomial pneumonia is $\sim 3-10 \%$ in patients undergoing NIV support $[38,118]$. The development of nosocomial pneumonia increases the risk of NIV failure, longer stays in hospital and increased mortality. Whether humidification increases the risk of nosocomial pneumonia is unknown, but basic infection control measures should be applied to all patients. These include hand hygiene of staff before and after contact with patient, respiratory hygiene and cough etiquette, barrier precautions and use of personal protective equipment when needed, macroscopic evaluation for any secretion/dirt of interface and the circuit and appropriate disinfection of equipment. Aspiration pneumonia may be another complication in patients who are comatose and/or incapable of protecting the upper airway. The risk increases with excessive gastric distention after NIV initiation. Although under-reported, 5\% of patients receiving NIV develop aspiration pneumonia [108]. In order to avoid this complication, it is important to remember to ensure that patients are positioned in a semirecumbent position during the application of NIV.

\section{Pneumothorax}

The incidence of pneumothorax is relatively low $(<5 \%)$ with NIV application $[119,120]$. The risk is especially increased in patients with a history of previous pneumothorax. Patients who describe acute chest pain and unexplained dyspnoea should be screened using chest radiography or ultrasound. Decrease of inspiratory and expiratory pressures, intercostal tube drainage and transfer to HDU/ICU because of high risk of NIV failure should be considered in the presence of pneumothorax [117].

\section{Conclusion}

NIV is a lifesaving therapeutic option, which should be proposed to the vast majority of patients with ARF. However, the benefits of NIV can be obtained only if adequate monitoring of patients is undertaken. The level of monitoring should depend on the severity of respiratory failure and the patient's general condition and should be enabled by appropriate location of the patient in the most suitable facility, such as the HDU or ICU. Because of the lack of strong scientific evidence concerning the optimal monitoring methods, it is usually left to the discretion of the clinician. Hence, staff experience in NIV is a key factor for success. The basis of monitoring patients treated with NIV is a regular assessment of patient's clinical status (vital signs; mainly respiratory rate, respiratory muscle effort and level of consciousness) and continuous monitoring of $\mathrm{SaO}_{2}$ and periodic $\mathrm{ABG}$ analysis. Taking into account the rapid technical development and accessibility of transcutaneous methods of measurement of $\mathrm{PaO}_{2}$ and $\mathrm{PaCO}_{2}$, we can expect that these techniques will soon become the gold standard. The important step in the course of treatment is the analysis in real time of the ventilatory parameters of the patient (VTE, leak and I:E ratio) provided by the ventilator as respiratory waveforms and numerical data.

\section{References}

1 Gregoretti C, Pisani L, Cortegiani A, et al. Noninvasive ventilation in critically ill patients. Crit Care Clin 2015; 31: 435-457.

2 Ozyilmaz E, Ugurlu AO, Nava S. Timing of noninvasive ventilation failure: causes, risk factors, and potential remedies. BMC Pulm Med 2014; 14: 19.

3 Curtis JR, Cook DJ, Sinuff T, et al. Noninvasive positive pressure ventilation in critical and palliative care settings: understanding the goals of therapy. Crit Care Med 2007; 35: 932-939.

4 Roberts CM, Stone RA, Buckingham RJ, et al. Acidosis, non-invasive ventilation and mortality in hospitalised COPD exacerbations. Thorax 2011; 66: 43-48.

5 Demoule A, Girou E, Richard JC, et al. Benefits and risks of success or failure of noninvasive ventilation. Intensive Care Med 2006; 32: 1756-1765.

6 Carlucci A, Delmastro M, Rubini F, et al. Changes in the practice of non-invasive ventilation in treating COPD patients over 8 years. Intensive Care Med 2003; 29: 419-425. 
Baumann HJ. The where-to-do-it of noninvasive ventilation revisited. Respir Care 2015; 60: 144-146. Corrado A, Roussos C, Ambrosino N, et al. Respiratory intermediate care units: a European survey. Eur Respir J 2002; 20: 1343-1350.

Hill NS. Where should noninvasive ventilation be delivered? Respir Care 2009; 54: 62-70.

Brochard L, Mancebo J, Wysocki M, et al. Noninvasive ventilation for acute exacerbations of chronic obstructive pulmonary disease. $N$ Engl J Med 1995; 333: 817-822.

Hilbert G, Gruson D, Vargas F, et al. Noninvasive ventilation in immunosuppressed patients with pulmonary infiltrates, fever, and acute respiratory failure. N Engl J Med 2001; 344: 481-487.

Antonelli M, Conti G, Bufi M, et al. Noninvasive ventilation for treatment of acute respiratory failure in patients undergoing solid organ transplantation: a randomized trial. JAMA 2000; 283: 235-241.

Auriant I, Jallot A, Hervé P, et al. Noninvasive ventilation reduces mortality in acute respiratory failure following lung resection. Am J Respir Crit Care Med 2001; 164: 1231-1235.

Conti G, Antonelli M, Navalesi $\mathrm{P}$, et al. Noninvasive vs. conventional mechanical ventilation in patients with chronic obstructive pulmonary disease after failure of medical treatment in the ward: a randomized trial. Intensive Care Med 2002; 28: 1701-1707.

Confalonieri M, Garuti G, Cattaruzza MS, et al. A chart of failure risk for noninvasive ventilation in patients with COPD exacerbation. Eur Respir J 2005; 25: 348-355.

Thille AW, Contou D, Fragnoli C, et al. Non-invasive ventilation for acute hypoxemic respiratory failure: intubation rate and risk factors. Crit Care 2013; 17: R269.

Iapichino G, Corbella D, Minelli C, et al. Reasons for refusal of admission to intensive care and impact on mortality. Intensive Care Med 2010; 36: 1772-1779.

Samuelson KA. Unpleasant and pleasant memories of intensive care in adult mechanically ventilated patients findings from 250 interviews. Intensive Crit Care Nurs 2011; 27: 76-84.

Samuelson KA, Lundberg D, Fridlund B. Stressful memories and psychological distress in adult mechanically ventilated intensive care patients - a 2-month follow-up study. Acta Anaesthesiol Scand 2007; 51: 671-678. 390: 156-168.

Girou E, Schortgen F, Delclaux C, et al. Association of noninvasive ventilation with nosocomial infections and survival in critically ill patients. JAMA 2000; 284: 2361-2367.

Scala R, Corrado A, Confalonieri M, et al. Increased number and expertise of Italian respiratory high-dependency care units: the second national survey. Respir Care 2011; 56: 1100-1107.

Elpern EH, Silver MR, Rosen RL, et al. The noninvasive respiratory care unit. Patterns of use and financial implications. Chest 1991; 99: 205-208.

Nicolini A, Ferrari MB. Evaluation of a transcutaneous carbon dioxide monitor in patients with acute respiratory failure. Ann Thorac Med 2011; 6: 217-220.

Bott J, Carroll MP, Conway JH, et al. Randomised controlled trial of nasal ventilation in acute ventilatory failure due to chronic obstructive airways disease. Lancet 1993; 341: 1555-1557.

Barbé F, Togores B, Rubí M, et al. Noninvasive ventilatory support does not facilitate recovery from acute respiratory failure in chronic obstructive pulmonary disease. Eur Respir J 1996; 9: 1240-1245.

Farha S, Ghamra ZW, Hoisington ER, et al. Use of noninvasive positive-pressure ventilation on the regular hospital ward: experience and correlates of success. Respir Care 2006; 51: 1237-1243.

Plant PK, Owen JL, Elliott MW. Early use of non-invasive ventilation for acute exacerbations of chronic obstructive pulmonary disease on general respiratory wards: a multicentre randomised controlled trial. Lancet 2000; 355: 1931-1935.

Lin SM, Liu KX, Lin ZH, et al. Does high-flow nasal cannula oxygen improve outcome in acute hypoxemic respiratory failure? A systematic review and meta-analysis. Respir Med 2017; 131: 58-64.

Ram FS, Lightowler JV, Wedzicha JA. Non-invasive positive pressure ventilation for treatment of respiratory failure due to exacerbations of chronic obstructive pulmonary disease. Cochrane Database Syst Rev 2003; 1: CD004104. Nava S, Hill N. Non-invasive ventilation in acute respiratory failure. Lancet 2009; 374: 250-259. exacerbations of COPD and varying levels of consciousness. Chest 2005; 128: 1657-1666.

Davidson AC, Banham S, Elliott M, et al. BTS/ICS guideline for the ventilatory management of acute hypercapnic respiratory failure in adults. Thorax 2016; 71: Suppl. 2, iil-i35.

Hilbert G, Navalesi P, Girault C. Is sedation safe and beneficial in patients receiving NIV? Yes. Intensive Care Med 2015; 41: 1688-1691.

Charlesworth M, Elliott MW, Holmes JD. Noninvasive positive pressure ventilation for acute respiratory failure in delirious patients: understudied, underreported, or underappreciated? A systematic review and meta-analysis. Lung 2012; 190: 597-603.

Chan KY, Cheng LS, Mak IW, et al. Delirium is a strong predictor of mortality in patients receiving non-invasive positive pressure ventilation. Lung 2017; 195: 115-125.

Roche Campo F, Drouot X, Thille AW, et al. Poor sleep quality is associated with late noninvasive ventilation failure in patients with acute hypercapnic respiratory failure. Crit Care Med 2010; 38: 477-485.

Carlucci A, Richard JC, Wysocki M, et al. Noninvasive versus conventional mechanical ventilation. An epidemiologic survey. Am J Respir Crit Care Med 2001; 163: 874-880.

Ely EW, Inouye SK, Bernard GR, et al. Delirium in mechanically ventilated patients: validity and reliability of the confusion assessment method for the intensive care unit (CAM-ICU). JAMA 2001; 286: 2703-2710.

Van de Louw A, Cracco C, Cerf C, et al. Accuracy of pulse oximetry in the intensive care unit. Intensive Care Med 2001; 27: 1606-1613.

Gehring $\mathrm{H}$, Hornberger $\mathrm{C}$, Matz $\mathrm{H}$, et al. The effects of motion artifact and low perfusion on the performance of a new generation of pulse oximeters in volunteers undergoing hypoxemia. Respir Care 2002; 47: 48-60.

Rice TW, Wheeler AP, Bernard GR, et al. Comparison of the $\mathrm{SpO}_{2} / \mathrm{FIO}_{2}$ ratio and the $\mathrm{PaO}_{2} / \mathrm{FIO}_{2}$ ratio in patients with acute lung injury or ARDS. Chest 2007; 132: 410-417.

Storre JH, Magnet FS, Dreher M, et al. Transcutaneous monitoring as a replacement for arterial $\mathrm{PCO}_{2}$ monitoring during nocturnal non-invasive ventilation. Respir Med 2011; 105: 143-150. 
Janssens JP, Howarth-Frey C, Chevrolet JC, et al. Transcutaneous $\mathrm{PCO}_{2}$ to monitor noninvasive mechanical ventilation in adults: assessment of a new transcutaneous $\mathrm{PCO}_{2}$ device. Chest 1998; 113: 768-773.

Cox M, Kemp R, Anwar S, et al. Non-invasive monitoring of $\mathrm{CO}_{2}$ levels in patients using NIV for AECOPD. Thorax 2006; 61: 363-364.

van Oppen JD, Daniel PS, Sovani MP. What is the potential role of transcutaneous carbon dioxide in guiding acute noninvasive ventilation? Respir Care 2015; 60: 484-491.

Ruiz Y, Farrero E, Córdoba A, et al. Transcutaneous carbon dioxide monitoring in subjects with acute respiratory failure and severe hypercapnia. Respir Care 2016; 61: 428-433.

Storre $\mathrm{JH}$, Steurer $\mathrm{B}$, Kabitz $\mathrm{H}$, et al. Transcutaneous $\mathrm{PCO}_{2}$ monitoring during initiation of noninvasive ventilation. Chest 2007; 132: 1810-1816.

Lermuzeaux M, Meric H, Sauneuf B, et al. Superiority of transcutaneous $\mathrm{CO}_{2}$ over end-tidal $\mathrm{CO}_{2}$ measurement for monitoring respiratory failure in nonintubated patients: a pilot study. J Crit Care 2016; 31: 150-156.

Gancel PE, Roupie E, Guittet L, et al. Accuracy of a transcutaneous carbon dioxide pressure monitoring device in emergency room patients with acute respiratory failure. Intensive Care Med 2011; 37: 348-351.

Janssens JP, Perrin E, Bennani I, et al. Is continuous transcutaneous monitoring of $\mathrm{PCO}_{2}\left(\mathrm{Tc}_{\mathrm{C}} \mathrm{CO}_{2}\right)$ over $8 \mathrm{~h}$ reliable in adults? Respir Med 2001; 95: 331-335.

Kelly AM, Klim S. Agreement between arterial and transcutaneous $\mathrm{PCO}_{2}$ in patients undergoing non-invasive ventilation. Respir Med 2011; 105: 226-229.

Westhoff M, Schönhofer B, Neumann P, et al. Nicht-invasive Beatmung als Therapie der akuten respiratorischen Insuffizienz. [Noninvasive mechanical ventilation in acute respiratory failure]. Pneumologie 2015; 69: 719-756.

Schwarz SB, Windisch W, Magnet FS, et al. Continuous non-invasive $\mathrm{PCO}_{2}$ monitoring in weaning patients: transcutaneous is advantageous over end-tidal $\mathrm{PCO}_{2}$. Respirology 2017; 22: 1579-1584.

Giner J, Casan P, Belda J, et al. Pain during arterial puncture. Chest 1996; 110: 1443-1445.

Zavorsky GS, Cao J, Mayo NE, et al. Arterial versus capillary blood gases: a meta-analysis. Respir Physiol Neurobiol 2007; 155: 268-279.

Ram FS, Picot J, Lightowler J, et al. Non-invasive positive pressure ventilation for treatment of respiratory failure due to exacerbations of chronic obstructive pulmonary disease. Cochrane Database Syst Rev 2004; 1: CD004104.

Moretti M, Cilione C, Tampieri A, et al. Incidence and causes of non-invasive mechanical ventilation failure after initial success. Thorax 2000; 55: 819-825.

Contal O, Vignaux L, Combescure $\mathrm{C}$, et al. Monitoring of noninvasive ventilation by built-in software of home bilevel ventilators: a bench study. Chest 2012; 141: 469-476.

Rabec C, Rodenstein D, Leger P, et al. Ventilator modes and settings during non-invasive ventilation: effects on respiratory events and implications for their identification. Thorax 2011; 66: 170-178.

Carteaux G, Lyazidi A, Cordoba-Izquierdo A, et al. Patient-ventilator asynchrony during noninvasive ventilation a bench and clinical study. Chest 2012; 142: 367-376.

Doorduin J, Sinderby CA, Beck J, et al. Automated patient-ventilator interaction analysis during neurally adjusted non-invasive ventilation and pressure support ventilation in chronic obstructive pulmonary disease. Crit Care 2014; 18: 550.

Ueno Y, Nakanishi N, Oto J, et al. A bench study of the effects of leak on ventilator performance during noninvasive ventilation. Respir Care 2011; 56: 1758-1764.

Nava S, Fanfulla F. The interfaces for NIV. In: Non Invasive Artificial Ventilation: How, When and Why. Springer-Verlag Italia, 2014; pp. 15-20

Berg KM, Lang GR, Salciccioli JD, et al. The rapid shallow breathing index as a predictor of failure of noninvasive ventilation for patients with acute respiratory failure. Respir Care 2012; 57: 1548-1554.

Respir J 2000; 15: 338-341
Cartucci A, Schriber A,

Carlucci A, Schreiber A, Mattei A, et al. The configuration of bi-level ventilator circuits may affect compensation for non-intentional leaks during volume-targeted ventilation. Intensive Care Med 2013; 39: 59-65. 1997; 10: 1663-1674.

Brochard L. Intrinsic (or auto-) PEEP during controlled mechanical ventilation. Intensive Care Med 2002; 28: $1376-1378$.

de Wit M, Miller KB, Green DA, et al. Ineffective triggering predicts increased duration of mechanical ventilation. Crit Care Med 2009; 37: 2740-2745.

Epstein SK. How often does patient-ventilator asynchrony occur and what are the consequences? Respir Care 2011; 56: 25-38.

Chao DC, Scheinhorn DJ, Stearn-Hassenpflug M. Patient-ventilator trigger asynchrony in prolonged mechanical ventilation. Chest 1997; 112: 1592-1599.

Thille AW, Lyazidi A, Richard JC, et al. A bench study of intensive-care-unit ventilators: new versus old and turbine-based versus compressed gas-based ventilators. Intensive Care Med 2009; 35: 1368-1376.

Vignaux L, Vargas F, Roeseler J, et al. Patient-ventilator asynchrony during non-invasive ventilation for acute respiratory failure: a multicenter study. Intensive Care Med 2009; 35: 840-846.

Colombo D, Cammarota G, Alemani M, et al. Efficacy of ventilator waveforms observation in detecting patient-ventilator asynchrony. Crit Care Med 2011; 39: 2452-2457.

Younes M, Brochard L, Grasso S, et al. A method for monitoring and improving patient:ventilator interaction. Intensive Care Med 2007; 33: 1337-1346.

Di Marco F, Centanni S, Bellone A, et al. Optimization of ventilator setting by flow and pressure waveform analysis during noninvasive ventilation for acute exacerbations of COPD: a multicentric randomized controlled trial. Crit Care 2011; 15: R283.

Esquinas AM, Scala R, Nasilowski J. Inspiratory pressure during noninvasive ventilation in stable COPD: help the lungs, but do not forget the heart. Eur Respir J 2013; 41: 764-765.

Lukácsovits J, Carlucci A, Hill N, et al. Physiological changes during low- and high-intensity noninvasive ventilation. Eur Respir J 2012; 39: 869-875. 
80 Valipour A, Schneider F, Kossler W, et al. Heart rate variability and spontaneous baroreflex sequences in supine healthy volunteers subjected to nasal positive airway pressure. J Appl Physiol 2005; 99: 2137-2143.

81 Diaz O, Iglesia R, Ferrer $\mathrm{M}$, et al. Effects of noninvasive ventilation on pulmonary gas exchange and hemodynamics during acute hypercapnic exacerbations of chronic obstructive pulmonary disease. Am J Respir Crit Care Med 1997; 156: 1840-1845.

82 Gomez H, Pinsky MR. Effects of mechanical ventilation on heart-lung interactions. In: Tobin M, ed. Principles and Practice of Mechanical Ventilation. 3rd Edn. MacGrawHill, 2012.

83 Hess DR. How to initiate a noninvasive ventilation program: bringing the evidence to the bedside. Respir Care 2009; 54: 232-243.

84 Caironi G, Gadda G, Rossi R, et al. Monitoring patients during noninvasive ventilation: the clinical approach. In: Esquinas AE, ed. Noninvasive Mechanical Ventilation Theory, Equipment, and Clinical Application. 2nd Edn. Springer, 2016.

85 Aliberti S, Messinesi G, Gamberini S, et al. Non-invasive mechanical ventilation in patients with diffuse interstitial lung diseases. BMC Pulm Med 2014; 14: 194.

86 Volpicelli G, Elbarbary M, Blaivas M, et al. International evidence-based recommendations for point-of-care lung ultrasound. Intensive Care Med 2012; 38: 577-591.

87 Xirouchaki N, Kondili E, Prinianakis G, et al. Impact of lung ultrasound on clinical decision making in critically ill patients. Intensive Care Med 2014; 40: 57-65.

88 Hew M, Tay TR. The efficacy of bedside chest ultrasound: from accuracy to outcomes. Eur Respir Rev 2016; 25: $230-246$.

89 Lichtenstein DA, Mezière GA. Relevance of lung ultrasound in the diagnosis of acute respiratory failure: the BLUE protocol. Chest 2008; 134: 117-125.

90 Zambon M, Greco M, Bocchino S, et al. Assessment of diaphragmatic dysfunction in the critically ill patient with ultrasound: a systematic review. Intensive Care Med 2017; 43: 29-38.

91 Umbrello M, Formenti P, Longhi D, et al. Diaphragm ultrasound as indicator of respiratory effort in critically ill patients undergoing assisted mechanical ventilation: a pilot clinical study. Crit Care 2015; 19: 161.

92 Matamis D, Soilemezi E, Tsagourias M, et al. Sonographic evaluation of the diaphragm in critically ill patients. Technique and clinical applications. Intensive Care Med 2013; 39: 801-810.

93 Goligher EC, Laghi F, Detsky ME, et al. Measuring diaphragm thickness with ultrasound in mechanically ventilated patients: feasibility, reproducibility and validity. Intensive Care Med 2015; 41: 642-649.

94 Antenora F, Fantini R, Iattoni A, et al. Prevalence and outcomes of diaphragmatic dysfunction assessed by ultrasound technology during acute exacerbation of COPD: a pilot study. Respirology 2017; 22: 338-344.

95 Fantini R, Mandrioli J, Zona S, et al. Ultrasound assessment of diaphragmatic function in patients with amyotrophic lateral sclerosis. Respirology 2016; 21: 932-938.

96 Vivier E, Mekontso Dessap A, Dimassi S, et al. Diaphragm ultrasonography to estimate the work of breathing during non-invasive ventilation. Intensive Care Med 2012; 38: 796-803.

97 Goligher EC, Fan E, Herridge MS, et al. Evolution of diaphragm thickness during mechanical ventilation. Impact of inspiratory effort. Am J Respir Crit Care Med 2015; 192: 1080-1088.

98 Kang HW, Kim TO, Lee BR, et al. Influence of diaphragmatic mobility on hypercapnia in patients with chronic obstructive pulmonary disease. J Korean Med Sci 2011; 26: 1209-1213.

99 Scheibe N, Sosnowski N, Pinkhasik A, et al. Sonographic evaluation of diaphragmatic dysfunction in COPD patients. Int J Chron Obstruct Pulmon Dis 2015; 10: 1925-1930.

100 Platz E, Merz AA, Jhund PS, et al. Dynamic changes and prognostic value of pulmonary congestion by lung ultrasound in acute and chronic heart failure: a systematic review. Eur J Heart Fail 2017; 19: 1154-1163.

101 Agricola E, Bove T, Oppizzi M, et al. "Ultrasound comet-tail images": a marker of pulmonary edema: a comparative study with wedge pressure and extravascular lung water. Chest 2005; 127: 1690-1695.

102 Alrajab S, Youssef AM, Akkus NI, et al. Pleural ultrasonography versus chest radiography for the diagnosis of pneumothorax: review of the literature and meta-analysis. Crit Care 2013; 17: R208.

103 Lichtenstein DA, Mezière G, Lascols N, et al. Ultrasound diagnosis of occult pneumothorax. Crit Care Med 2005; 33: $1231-1238$.

104 Oveland NP, Lossius HM, Wemmelund K, et al. Using thoracic ultrasonography to accurately assess pneumothorax progression during positive pressure ventilation: a comparison with CT scanning. Chest 2013; 143: 415-422.

105 Scala R, Naldi M, Maccari U. Early fiberoptic bronchoscopy during non-invasive ventilation in patients with decompensated chronic obstructive pulmonary disease due to community-acquired-pneumonia. Crit Care 2010; 14: R80.

106 Agarwal R, Khan A, Aggarwal AN, et al. Bronchoscopic lung biopsy using noninvasive ventilatory support: case series and review of literature of NIV-assisted bronchoscopy. Respir Care 2012; 57: 1927-1936.

107 Korkmaz Ekren P, Basarik Aydogan B, Gurgun A, et al. Can fiberoptic bronchoscopy be applied to critically ill patients treated with noninvasive ventilation for acute respiratory distress syndrome? Prospective observational study. BMC Pulm Med 2016; 16: 89.

108 Carron M, Freo U, BaHammam AS, et al. Complications of non-invasive ventilation techniques: a comprehensive qualitative review of randomized trials. Br J Anaesth 2013; 110: 896-914.

109 Hess DR. Patient-ventilator interaction during noninvasive ventilation. Respir Care 2011; 56: $153-165$.

110 Nava S. Behind a mask: tricks, pitfalls, and prejudices for noninvasive ventilation. Respir Care 2013; 58: 1367-1376.

111 Pisani L, Mega C, Vaschetto R, et al. Oronasal mask versus helmet in acute hypercapnic respiratory failure. Eur Respir J 2015; 45: 691-699.

112 Liu Q, Gao Y, Chen R, et al. Noninvasive ventilation with helmet versus control strategy in patients with acute respiratory failure: a systematic review and meta-analysis of controlled studies. Crit Care 2016; $20: 265$.

113 Navalesi P, Costa R, Ceriana P, et al. Non-invasive ventilation in chronic obstructive pulmonary disease patients: helmet versus facial mask. Intensive Care Med 2007; 33: 74-81.

114 Esquinas Rodriguez AM, Papadakos PJ, Carron M, et al. Clinical review: helmet and non-invasive mechanical ventilation in critically ill patients. Crit Care 2013; 17: 223. 
115 Olivieri C, Longhini F, Cena T, et al. New versus conventional helmet for delivering noninvasive ventilation: a physiologic, crossover randomized study in critically ill patients. Anesthesiology 2016; 124: 101-108.

116 Ozsancak A, Sidhom SS, Liesching TN, et al. Evaluation of the total face mask for noninvasive ventilation to treat acute respiratory failure. Chest 2011; 139: 1034-1041.

117 Gay PC. Complications of noninvasive ventilation in acute care. Respir Care 2009; 54: 246-257.

118 Zhang Z, Duan J. Nosocomial pneumonia in non-invasive ventilation patients: incidence, characteristics, and outcomes. J Hosp Infect 2015; 91: 153-157.

119 Mehta S, Hill NS. Noninvasive ventilation. Am J Respir Crit Care Med 2001; 163: 540-577.

120 Mollica C, Brunetti G, Buscajoni M, et al. Non-invasive pressure support ventilation in acute hypoxemic (non hypercapnic) respiratory failure. Observations in respiratory intermediate intensive care unit. Minerva Anestesiol 2001; 67: 107-115.

121 Kelly BJ, Matthay MA. Prevalence and severity of neurologic dysfunction in critically ill patients. Influence on need for continued mechanical ventilation. Chest 1993; 104: 1818-1824.

122 Antonelli M, Conti G, Moro ML, et al. Predictors of failure of noninvasive positive pressure ventilation in patients with acute hypoxemic respiratory failure: a multi-center study. Intensive Care Med 2001; 27: 1718-1728.

123 Agarwal R, Handa A, Aggarwal AN, et al. Outcomes of noninvasive ventilation in acute hypoxemic respiratory failure in a respiratory intensive care unit in north India. Respir Care 2009; 54: 1679-1687.

124 Carron M, Freo U, Zorzi M, et al. Predictors of failure of noninvasive ventilation in patients with severe community-acquired pneumonia. J Crit Care 2010; 25: 540. 